\title{
Management practice adoption and productivity of commercial aquaculture farms in selected areas of Bangladesh
}

\author{
Md. Masudul Haque Prodhan and Md. Akhtaruzzaman Khan
}

Department of Agricultural Finance, Bangladesh Agricultural University, Mymensingh-2202, Bangladesh

\section{ARTICLE INFO}

Article history:

Received: 27 February 2018

Accepted: 15 April 2018

Keywords:

Management Practice Adoption,

Productivity, Aquaculture,

Bangladesh

Correspondence:

Md. Akhtaruzzaman Khan

(azkhan13@yahoo.com)

\begin{abstract}
Adoption of scientific management practice is the pre-condition for increasing productivity in any farm business. This study estimates the level of scientific aquaculture management practice (SAMP) adoption, factor affecting adoption and its relation with productivity. Sixty aquaculture farms were selected from 3 upazilas of Mymensingh district of Bangladesh. Adoption level was measured by following Sengupta (1967) while Tobit regression was used to assess the determinants of adoption level. Polynomial regression was employed to show the relationship among farm size, adoption level and productivity. Result revealed that average SAMP adoption level was $54 \%$ where $53 \%$ farmers were medium adopter. Training, experience, education and extension service had significant positive effect on level of adoption. Productivity was significantly higher for those farmers who adopted more SAMP. Adoption level, productivity and profitability of small farmers were higher than that of large farmers. The study suggests farmers for adopting scientific management practices in order to increase the aquaculture productivity and profitability.
\end{abstract}

\section{Introduction}

Aquaculture has expanded tremendously in Bangladesh and achieved 5th position in the world accounting for $2.43 \%$ of the total global aquaculture production $(\mathrm{MoF}$, 2016). This sector plays a significant role for reducing protein deficiency and malnutrition, generating employment and earnings foreign exchange. Aquaculture productivity needs to be increased to fulfill the excess demand of growing population. But productivity mainly depends on appropriate use of different inputs and management practices. Feed is the main input of fish production which captures about 70\% of total production cost (Khan et. al. 2017, Alam et. al. 2012, Alam 2011). Fertilizer is applied to raise the phytoplankton in the pond. Good quality fingerling is another important input which moves-up the productivity of aquaculture. Farmers should be very cautious about the stocking density of fingerlings because over-populated ponds make aquaculture species susceptible to disease, less growth and death. Different water cleaning measures like removal of sediment, water exchange, salt and lime ensure good water quality which reduces harmful gas, disease prevalence and mortality rate. Culture system such as monoculture and polyculture also affects the aquaculture productivity. Farmers of developed countries follow the rules of scientific aquaculture management practices (SAMP) while farmers of developing countries are not capable to utilize all the management practices. Available information, access to information, necessary extension service and training are very important for adopting the SAMP. Furthermore, adoption of SAMP may be affected by different socioeconomic characteristics of the producers.
There are few studies on technology and management practice adoption in the field of agriculture and aquaculture. Sreenivasa \& Hiriyanna (2014) studied factors influencing adoption in non-traditional Seri culture with respect to mulberry and silkworm rearing technologies and found that education, farming experience and extension service significantly influenced the adoption of new technologies irrespective of holding size groups. Swathi et al. (2011) found that adoption behavior was high in harvesting, conditioning, sterilization, liming and feed management in scientific shrimp farms. Arora et al. (2009) observed stronger relation between adoption index and composite index of infrastructure which emphasized the need for improving infrastructure to increase adoption of agricultural technologies. Like these studies, Karunathilaka \& Thayaparan (2016), Gedikoglu (2010),Singh et al. (2014) and Ndambiri et al. (2008) also dealt with adoption of improved technologies in different aspects of agriculture and aquaculture. But adoption level of SAMP and its relationship with productivity is almost absent in Bangladesh. Therefore, this study bears prime importance in assisting aquaculture farmers are regarding necessity of adopting SAMP in their operation. The specific objectives of the study are: (i) to estimate the level of SAMP adoption and identifying factors affecting adoption, (ii) to assess the relationship among adoption level, farm size and productivity in aquaculture farming. 


\section{Materials and Methods}

The study was based on the primary data collected from 60 aquaculture farms located in 3 major aquaculture producing upazilas (Trishal, Fulpur and Tarakanda) of Mymensingh district of Bangladesh. Pangas and tilapia were dominating species which contributes more than $40 \%$ of total aquaculture production in the study area. Therefore, pangas farm was chosen with mono and polyculture system. The farms were selected by using stratified random sampling technique from the lists provided by Upazila Fisheries Officer (UFO) and data were collected following face to face interview with pretested questionnaire in 2015. Fifteen aquaculture management practices were considered as presented in Table 1 . These management practices were coded as ' 1 ' for the response "who use less than the recommended dose", '2' for "who use more than recommended dose" and ' 3 ' for "who use same as recommended dose". Some management practices like weed control, dyke rising, species combination (surface, mid and bottom), feeding as per body weight, water quality test and maintain record book were coded as ' 1 ' for the positive response and ' 0 ' for the negative response.

Table 1. Management practices to determine the level of adoption

\begin{tabular}{lc}
\hline Management practices & $\begin{array}{c}\text { Recommended } \\
\text { dose }\end{array}$ \\
\hline Removal of sediment per month(times) & 1 \\
Liming (gm/decimal) & 1000 \\
Cow dung (kg/decimal) & $5000-10000$ \\
Urea (gm/decimal) & $100-150$ \\
TSP (gm/decimal) & $50-75$ \\
Fingerling stocking density (per decimal) & $175-195$ \\
Fingerling size (inch) & $4-8$ \\
Feeding (times/day) & 2 \\
Water exchange (frequency per year) & 1 to 2 \\
Weed control (dummy) & $\mathrm{Yes}=1, \mathrm{No}=0$ \\
Dyke rising (dummy) & $\mathrm{Yes}=1, \mathrm{No}=0$ \\
Species combination (dummy, 1 if they & $\mathrm{Yes}=1, \mathrm{No}=0$ \\
follows species combination on the basis & \\
of water depth, 0 otherwise) & \\
Feeding as per body weight (dummy) & $\mathrm{Yes}=1, \mathrm{No}=0$ \\
Test water quality (dummy) & $\mathrm{Yes}=1, \mathrm{No}=0$ \\
Maintain record book (dummy) & $\mathrm{Yes}=1, \mathrm{No}=0$ \\
\hline
\end{tabular}

Source: BFRI, 2014

The obtained responses from above management practices were considered as individual adoption score and were used for calculating the adoption level following Sengupta(1967) as follows:

Adoption quotient or level $=$

$$
\frac{\text { Total score obtained by farmer }}{\text { Maximum score }} \times 100
$$

Again, the adoption quotient/level was classified as high adopters $(66.67 \%$ to $100 \%)$, medium adopters $(33.34 \%$ to $66.66 \%$ ) low adopters (up to $33.33 \%$ ) and nonadopters (0).

In addition, Tobit model was used to identify the factors affecting adoption level of SAMP. Hence adoption level ranged from 27.77 to 88.89 therefore, Tobit model was a better choice for this data set. The empirical Tobit regression model was as follows:

$$
\begin{array}{r}
Y=\alpha_{0}+\beta_{1} X_{1}+\beta_{2} X_{2}+\beta_{2} X_{2}+\beta_{4} X_{4}+\beta_{5} X_{5}+ \\
\beta_{6} X_{6}+\beta_{7} X_{7}+e
\end{array}
$$

Where; $Y=$ level of adoption; $\alpha_{0}=$ intercept; $\beta=$ coefficient; $\mathrm{X}_{1}=$ age (year); $\mathrm{X}_{2}=$ education (years of schooling); $X_{3}=$ family size (number); $X_{4}=$ experience (years); $\mathrm{X}_{5}=$ training (dummy; $1=$ if training has received and $0=$ otherwise); $X_{6}=$ farm distance from home $(\mathrm{km}) ; \mathrm{X}_{7}=$ extension services (dummy; $1=$ if extension service has received and $0=$ otherwise) and $\mathrm{e}=$ error term.

Furthermore, polynomial regression model was employed to show the relationship between farm size, productivity and adoption level. Theoretical polynomial regression smoothing model can be describe as:

Consider a set of scatter plot data $\left\{\left(x_{1}, y_{1}\right), \ldots,\left(x_{n}, y_{n}\right)\right\}$ from the model

$y_{i}=m\left(x_{i}\right)+\delta\left(x_{i}\right) \varepsilon_{i}$

for some unknown mean and variance functions $m(\cdot)$ and $\sigma^{2}(\cdot)$, and symmetric errors $\varepsilon_{i}$ with $\mathrm{E}\left(\boldsymbol{\varepsilon}_{i}\right)=0$ and $\operatorname{Var}\left(\varepsilon_{i}\right)=1$. The goal is to estimate $\mathrm{m}\left(\mathrm{x}_{0}\right)=\mathrm{E}[\mathrm{Y} \mid \mathrm{X}=$ $\mathrm{x}_{0}$ ], making no assumption about the functional form of $m(\cdot)$.

\section{Results and Discussion}

\section{Socio-economic characteristics of farmers}

Farmers' adoption of SAMP was highly influenced by socio-economic status which changes over time (Olaoye et al. 2016). Study found that the mean age of farmers was 38 years while their level of education was 8 years (Table 2). In addition, experience in aquaculture farming found on an average 3.52 years. Alam, (2011) found the similar mean education and age of pangas farmers in Bangladesh but mean experience of farmers was much higher than the study. Average family size found 4.97 which is greater than national average (BBS, 2016). Although dependent members was more in the large family, but they worked as family labor in aquaculture ponds and thus reduce labor cost as well as enhance productivity. 
Table 2. Descriptive statistics of socio-economic characteristics of aquaculture farmers

\begin{tabular}{lcccc}
\hline Variables & Mean & SD & \multicolumn{2}{c}{ Minimum Maximum } \\
\hline Area of farm (decimal) & 201 & 162 & 40 & 750 \\
Age (years) & 38.1 & 7.053 & 27 & 51 \\
Education (years) & 8.13 & 3.27 & 3 & 16 \\
Experience (years) & 3.52 & 1.93 & 1 & 10 \\
Family size (number) & 4.97 & 1.22 & 2 & 8 \\
Training (dummy,\% of & 30 & - & 0 & 1 \\
positive response) & & & & \\
Farm distance (km) & 1.35 & 1.06 & 0.25 & 6 \\
$\begin{array}{l}\text { Extension service } \\
\text { (dummy, \% of positive }\end{array}$ & 10 & - & 0 & 1 \\
response) & & & & \\
\hline
\end{tabular}

Source: Field Survey, 2015

About $30 \%$ farmers received training on aquaculture production whereas only $10 \%$ received extension facilities. Generally, Department of Fisheries (DoF) or other related international and national research organization provides training on aquaculture. Participation in this aquaculture training mainly depends on farmers' communication with training organization. Therefore, comparatively large farmers those have good communication with these organizations takes opportunity to participate in the training program.

\section{Profitability of aquaculture}

Profitability analysis shows the financial situation of aquaculture farms whether farming is economically feasible or not. Result found that per hectare total cost of aquaculture was Tk. 2250358. Feed was the single largest cost item which consisted about $77.77 \%$ of total cost while Khan (2012) and Alam (2011) found that feed occupied $71 \%$ and $70 \%$ respectively. Although feed was the main input for aquaculture but its cost is increasing year by year due to rising price of different raw materials.

Table 3. Cost-benefit analysis of commercial aquaculture farming (per hectare)

\begin{tabular}{lccc}
\hline Item & Quantity & $\begin{array}{c}\text { Cost/return } \\
\text { (Tk) }\end{array}$ & $\begin{array}{c}\% \text { of } \\
\text { costs }\end{array}$ \\
\hline Cost & & & \\
Labor (man-day) & 897 & 248717 & 11.05 \\
Fingerlings (no.) & 43733 & 119148 & 5.29 \\
Feed (kg) & 63881 & 1727785 & 76.77 \\
Urea (kg) & 21 & 400 & 0.01 \\
TSP (kg) & 4 & 164 & 0.007 \\
Cow-dung (kg) & 744 & 232 & 0.01 \\
Lime (kg) & 366 & 6483 & 0.28 \\
Pesticide (Tk) & & 5883 & 0.26 \\
Miscellaneous cost (Tk) & & 83501 & 3.71 \\
Total variable cost (Tk) & & 2192313 & 97.43 \\
Total fixed cost (Tk) & & 58045 & 2.57 \\
Total cost (Tk) & & 2250358 & 100 \\
Return & & 33642 & \\
Total harvest (kg/hectare) & & 3136880 & \\
Gross return (Tk/hectare) & & 944567 & \\
Gross Margin (Tk/hectare) & & 886522 & \\
Net return (Tk/hectare) & & 1.39 \\
BCR (total return/total cost) & & \\
\hline Source Fien Survey, 2015 & & \\
\hline
\end{tabular}

Source: Field Survey, 2015
Labor was the second highest cost that captured $11.05 \%$ of total production cost. This input was essential for maintaining all SAMPs. Fingerling captured $5.29 \%$ of total cost. Per hectare productivity of aquaculture was found about $33642 \mathrm{~kg}$ and this finding is consistent with the studies of Khan et al. (2017), Alam (2011), Ali et al. (2013) and Ali \& Haque (2011). Result showed that net return or profit from per hectare of pond area was about Tk 886522 and the BCR was1.39. It implies that farmers can earn profit Tk. 0.39 by investing Tk. 1 which indicates aquaculture was a profitable business in the study area. Ajiboye et al. (2011) and Thompson \& Mafimisebi (2014) found the identical result in their analyses.

\section{Level of management practice adoption}

Adoption level for an individual farmer was computed from the adoption scores gained by the farmer. Result reveals that $23.33 \%$ farmers were high adopter while $53.33 \%$ were medium adopter. Result also showed that average adoption level is $54 \%$ which lied in the medium level $(33.34 \%$ to $66.66 \%)$. Percentage of high adopted farms was low because of less adoption of different scientific management practices. Among these practices, farmers were struggling to follow timely feed application because most of the farmers were not always able to afford the cost of the feed. This situation arisen due to change in feed price. This result consistent with the study of Gawde et al. (2006).

Table 4. Adoption level of aquaculture management practice

\begin{tabular}{lcc}
\hline Adoption level category & $\begin{array}{c}\% \text { of } \\
\text { farmers }\end{array}$ & $\begin{array}{c}\text { Obtained } \\
\text { level }\end{array}$ \\
\hline No adopters (0) & 0.00 & 0.00 \\
Low adopter (up toto 33.33) & 23.33 & 31.15 \\
Medium adopter (33.34\% to 66.66\%) & 53.33 & 54.60 \\
High adopter (66.67\% to $100 \%)$ & 23.33 & 76.98 \\
Average & & 54.35 \\
\hline
\end{tabular}

Source: Field Survey, 2015

Factors affecting adoption of aquaculture management practices

Adoption level of aquaculture management practices may depend on socioeconomic characteristics of the producers.

Table 5. Tobit regression for factors affecting adoption of scientific aquaculture management practices

\begin{tabular}{lccc}
\hline Adoption & Coefficient & Standard error & P-value \\
\hline Constant & 34.89 & 13.94 & 0.01 \\
Age & -0.14 & 0.23 & 0.54 \\
Education & $1.28^{* *}$ & 0.59 & 0.03 \\
Family size & 0.95 & 1.63 & 0.55 \\
Experience & $1.84^{* *}$ & 0.91 & 0.04 \\
Training & $10.17^{* * *}$ & 4.14 & 0.01 \\
Farm distance & $-2.86^{* *}$ & 1.42 & 0.05 \\
Extension service & $8.64^{*}$ & 4.61 & 0.06 \\
Lr chi $^{2}$ & \multicolumn{2}{c}{58.22} \\
${\text { Prob }>\text { chi }^{2}}^{2} 0.00$ & \\
\hline
\end{tabular}

Significance level: *** for $1 \%, * *$ for $5 \%$ and $*$ for $10 \%$ 
Education was found significant positive effect on adoption level i.e. highly educated farmers were more adopter compared to the less educated (Table 5). Usually, educated farmers participate in different seminars, symposiums and workshops and thus can recognize different aspects of SAMP. CIMMYT (1993) also carried out a research and found similar result. Training shows significant positive effect on adoption implying that farmer who received training was more adopter compared to non-receiver. Farmers can learn different management techniques from training programs provided by government and different NGOs. Sakiband Afrad (2014), Njankoua et al. (2012), Bucciarelli et al. (2010), Kashem (2005), Tziraki et al. (2000) and Hussain et al. (1994) got similar result for education and training. Besides, positive and significant coefficient of extension services implies that the farmers those had better communication with extension services providers were higher adopter. Especially, extension agent, technician and resource person provided necessary suggestions on different management practices and those services enhanced aquaculture productivity. Ragasa et al. (2013) and Perey (2016) identified the positive relation between adoption level and extension services. Experience of aquaculture farmers also had positive significant effect on adoption level. Generally, experienced farmer have vast knowledge about the management practices due to learning by doing. Distance from farm to residence had negatively significant effect on adoption level implied that the higher distance, the lower the adoption. If the farm is situated in distant places, it becomes difficult to manage. Normally, farmers apply feed in the pond two times in a day. When it is far from home, it was difficult for them to provide feed timely. Moreover, they cannot apply medicines in their pond at the time of disease prevalence. Hailu et al. (2014) found the identical result on the effect of distance on adoption level.

\section{Relationship between farm size and adoption level}

Local polynomial regression showed that farm size and adoption level was inversely related. i.e. adoption level decrease with increase in farm size (Figure 1). More labor and capital was needed to maintain the large farm. But credit constraint was one of the main problems for large aquaculture farm for maintaining the appropriate input application. As discussed earlier, feed was the main input and occupied two third of the total production cost, therefore large farmer couldn't apply appropriate amount of feed during culture period. On the other hand, more labor was need for application of input and other management of farm, especially for security purpose. But large farmers were not able to adopt in scientific way due to scarcity of labor. This result was consistent with Andrei (2011), Ureta et al. (2006) and Just \& Zilberman, (1983).

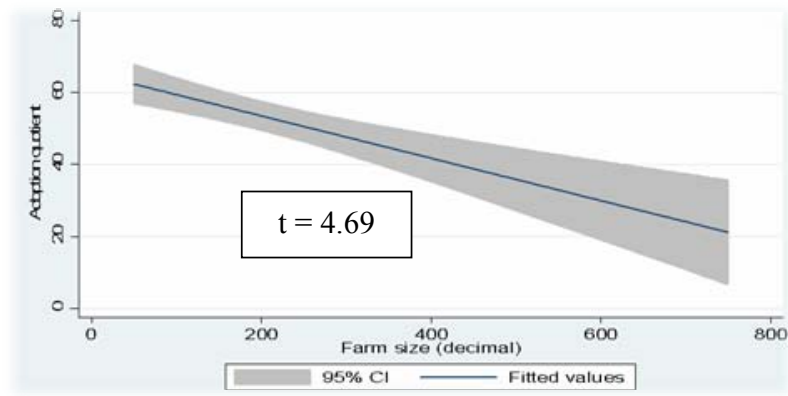

Figure 1. Relationship between farm size and adoption level

Relationship between farm size and productivity

The relationship between farm size and land productivity has been widely debated and several reasons and explanations for the inverse relationship had been put forward and tested. Imperfect factor market was the main issue for the debate. Local polynomial regression in Figure 2 revealed the inverse relationship between farm size and productivity. The probable reason might be the small farmers can easily supervise their farms. They got a relative advantage of using more family labor that reduce the monitoring and supervision costs of hired labor with respect to the large farms (Thapa, 2007). In addition, large farms were overusing fertilizer, pesticides, etc. which led to the degradation of their natural resource that causes less productivity (Sial et al., 2012). In developing countries, this inverse relation was found by Desiere (2016), Gaurav \& Mishra (2014), Bhalla \& Roy (1988), Feder (1985) and Fan \& ChanKang (2003). Nevertheless, Sadhu \& Singh (1996) found positive relation between farm size and productivity.

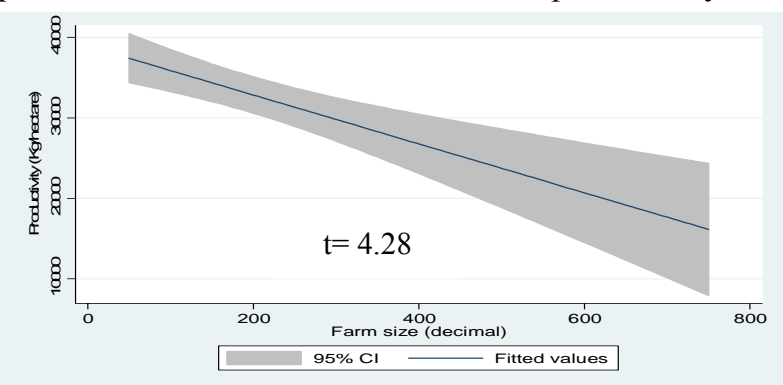

Figure 2. Relationship between farm size and productivity

Relationship between adoption level and productivity There is no doubt that management practices was linked to the productivity. A lot of technologies has been introduced by research institutes under the Government of Bangladesh and other related organizations which concerned with innovations. Theory tells that innovative management practices affect the productivity in the aquaculture sector. Local polynomial regression depicts a positive relationship between adoption level and productivity implying that productivity was significantly higher for those farmers who adopted SAMP (Figure 3). Ahmed (2015) found similar result in the case of maize production. Gray \& Shadbegian (1998), Thapa (2007), Belay et al. (2014), Moreno and Surinach (2014), Asfaw \& Shiferaw (2010) also found that productivity of high adopters were greater than that of less adopter. 


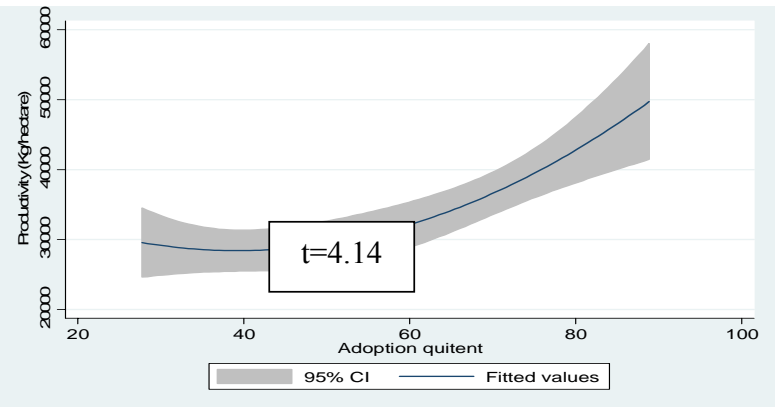

Figure 3. Relationship between adoption level and productivity

A summary of the results depicted in Table 6. It reveals that productivity, total return and profit of high adopter farmers were higher than others. Farm size of high adopters was small and was more productive and profitable. In addition, BCR was found more in case of high adopter compared to others. Overall, the result indicated that SAMP has enhanced the productivity and profitability in aquaculture. Ansah (2014), Adeshinwa \& Bolorunduro (2007) and Thompson \& Mafimisci (2014) found that adoption level, farm size and productivity were affected by each other.

Table 6. Summary statistics of adoption level, farm size, productivity and profitability

\begin{tabular}{lccc}
\hline Item & Low adopter & Medium adopter & High adopter \\
\hline Area (decimal) & 270 & 186.87 & 164.28 \\
Yield (kg/ha) & 33754 & 32548 & 36034 \\
Total return (Tk) & 3059138 & 3047368 & 3419223 \\
Profit (Tk) & 782550 & 810739 & 1163691 \\
BCR & 1.34 & 1.36 & 1.51 \\
\hline
\end{tabular}

Source: Field Survey, 2015

\section{Conclusion and policy recommendation}

Adoption of SAMP is essential for increasing the productivity of any farm business. This study tried to estimates the level of adoption of scientific aquaculture management practices, factors affecting adoption and its relation with farm size and productivity. For this purpose, 60 aquaculture farms were selected from Mymensingh district of Bangladesh. Aquaculture farming was found profitable in the study area. In terms of adoption, average adoption level of SAMP was about $54 \%$ while $53 \%$ farmers were medium adopter. Training, experience, education and extension service had significant positive effect on adoption level while farm distance from home and age of the aquaculture fish farmers had negative effect. Adoption level and farm size were inversely associated implying that small farmers were relatively higher adopter compared to larger ones. High adoption level was positively related with productivity and profitability of aquaculture farming. In order to enhance the aquaculture productivity, farmers are suggested to adopt scientific management practices. Department of Fisheries (DoF), Bangladesh Fisheries Research Institute (BFRI) and other related organizations can prepare and distribute leaflet on SAMP and production system. In addition, training on scientific aquaculture production system and extension services needs to expand all over the country.

\section{Acknowledgment}

Authors acknowledged their thanks to the BANGFISH project ('Upgrading pangas and tilapia value chains in Bangladesh' which is funded by DANIDA) for funding the research and also the aquaculture farmers of Mymensingh district for sharing information and providing valuable inputs. The authors are grateful to the anonymous reviewers for their constructive comments and suggestions to improve the paper.

\section{Reference}

Adeshinwa, A.O.K. and Bolorunduro, P.I.2007. Existing fisheries technologies and approaches for dissemination in two maritime States of Nigeria: Effectiveness and constraints. American-Eurasian J. Agric\& Environ. Sci., 2 (3): 231-239.

Ahmed, M.H. 2015. Adoption of multiple agricultural technologies in maize production of the Central Rift Valley of Ethiopia. Agricultural Economics., 117: 162-168.

Ajiboye., John, A., Awoyemi. and Timothy, T. 2011. Analysis of Profitability of Fish Farming Among Women in Osun State, Nigeria. Journal of Economics and Sustainable Development., 2(4): 2222-2855.

Alam, F.2011. Measuring technical: Allocative and cost efficiency of pangas (Pangasius hypothalamus: Sauvage 1878) fish farmers of Bangladesh. Aquaculture., 42: 1487-1500.

Ali, H., Haque, M.M. and Belton, B. 2013. Striped catfish (P. hypophthalmus) aquaculture in Bangladesh: an overview. Aquaculture research.,44. 950-965.

Ali, H. and Haque, M. M. 2011. Impacts of Pangasius aquaculture on land use patterns in Mymensingh district of Bangladesh. $J$. Bangladesh Agril. Univ. 9(1): 169-178.

Andrei, P. 2011.Agricultural Technology Adoption: Issues for Consideration When Scaling-Up. The Cornell Policy Review. Journal of the Cornell Institute for Public Affairs., 1.

Ansah, Y.B. 2014. Enhancing Profitability of Pond Aquaculture in Ghana through Resource Management and Environmental Best Management Practices. Doctor of Philosophy in Fisheries and Wildlife, October 30, www.researchgate.net

Asfaw, S. and Shiferaw, B. 2010. Agricultural technology adoption and rural poverty: Application of an endogenous switching regression for selected East African Countries. Poster Presented at the Joint 3rd African Association of Agricultural Economists (AAAE) and $48^{\text {th }}$ Agricultural Economists Association of South Africa (AEASA) Conference, Cape Town. New Economics Papers., 97049.

Arora, A., Rajni, J. and Raju, S.S. 2009. A Novel Adoption Index of Selected Agricultural Technologies: Linkages with Infrastructure and Productivity. Agricultural Economics Research Review.,22(1): 109-120.

BBS, Bangladesh Bureau of Statistics, Government of the people's republic of Bangladesh, 2016

Belay, A.M., Kasie, F.M., Helo, P., Takala, J. and Powell, D.J. 2014. Adoption of quality management practices: An investigation of its relationship with labor productivity for labor intensive manufacturing companies. Benchmarking: An International Journal., 21 (1): 21-24.

BFRI. 2014. Leaflet on aquaculture production, Bangladesh Fisheries Research Institute, Government of the people's republic of Bangladesh.

Bhalla, S.S., and Roy, P. 1988. Mis-Specification in Farm Productivity Analysis: the Role of Land Quality. Oxford Economic Papers., 40 (1): 55-73.

Bucciarelli, E., Odoardi, L. and Muratore, F. 2010. What role for education and training in technology adoption under an advanced socio-economic perspective? Procedia-Social and Behavioral Sciences., 9: 573-578. 
CIMMYT. 1993. The adoption of agricultural technology: A Guide for survey design. CIMMYT Economic Programme, Mexico.

Desiere, S. 2016.The inverse productivity size relationship: can it be explained by systematic measurement error in self-reported production? Submission to the 5th International Conference of the African Association of Agricultural Economists (ICAAAE), Addis Ababa, Ethiopia, September 23-26.

Fan, S., and Chan-Kang, C. 2003. Is small beautiful? Farm size, productivity, and poverty in Asian agriculture. Agricultural Economics. 32 (1): 135-146.

Feder, G.1985. The Farm Size and Farm Productivity: the Role of Family Labour, Supervision and Credit Constraints. Journal of Development Economics., 18: 297-313.

Gaurav, S. and Mishra, S. 2014. Farm Size and Returns to Cultivation in India: Revisiting an Old Debate. Oxford Development Studies., 1-29.

Gawde, M.M., Chandge, M.S.N. and Shirdhankar, M.M. 2006. Adoption of improved aquaculture practices by shrimp farmers in south konkan region Maharashtra, India. Journal of Agriculture and Social Research (JASR)., 6(2).

Gedikoglu, H. 2010.Impact of Farm Size and Uncertainty on Technology Disadoption, Selected Paper prepared for presentation at the Southern Agricultural Economics Association Annual Meeting, Orlando.

Gray, W. and Shadbegian, R. 1998. Environmental Regulation, Investment Timing, and Technology Choice. Journal of Industrial Economics.,46(2): 235-256.

Hailu, B.K., Abrha, B.K. and Weldegiorgis, K.A. 2014. Adoption and impact of agricultural technologies on farm income: evidence from southern Tigray, Northern Ethiopia. International Journal of Food and Agricultural Economics.,2(4): 91-106.

Hussain, S.S., Byerlee, D. and Heisey, P.W. 1994. Impacts of the training and visit extension system on farmers' knowledge and adoption of technology: Evidence from Pakistan. Agricultural Economics., 10: 39-47.

Just, R.E. and Zilberman, D. 1983. Stochastic structure, farm size and technology adoption in developing agriculture. Oxford Economic Papers., 35(2): 307-328.

Karunathilaka, D.D.D.S. and Thayaparan, A. 2016. Determinants of Farmers' Perceptions towards the Adoption of New Farming Techniques in Paddy Production in Sri Lanka. Journal of Economics and Sustainable Development., 7(12): 2222-2855.

Kashem, M.A. 2005. Bangladesh Factors affecting the adoption of aquaculture technologies by the farmers. Fish. Res. 9(1): $77-79$.

Khan, A., Guttormsen, A. and Roll, K.H. 2017. Production risk of pangas (Pangasius hypophthalmus) fish farming in Bangladesh, Aquaculture Economics and Management., $1-17$

Khan, A. 2012. Efficiency, risk and management of fisheries sector in Bangladesh, Philosophiae Doctor (PhD) Thesis, Norwegian University of Life Sciences, Norway.

MoF. 2015-16. Bangladesh Economic Review, Finance Division, Ministry of Finance, and Government of the people's republic of Bangladesh.

Moreno, R. and Surinach, J. 2014. Innovation Adoption and Productivity Growth: Evidence for Europe. Research Institute of Applied Economics Working Paper. 86(2): 6287.

Njankoua, W.D., Pouomogne, V., Nyemeck, B.J. and Yossa, N.R 2012. Farmer's Perception and Adoption of New Aquaculture Technologies in the Western Highlands of Cameroon. Tropicultura.,30(3): 180-184.
Ndambiri, H.K., Ritho, C.N. and Mbogoh, S.G. 2008. An evaluation of farmers' perceptions of and adaptation to the effects of climate change in Kenya.International Journal of Food and Agricultural Economics., 1(1): 75-96.

Olaoye, OJ., Ezeri, G.N.O., Akegbejo-Samsons, Y., Awotunde, J.M.and Ojebiyi, W.G. 2016. Dynamics of the adoption of improved aquaculture technologies among fish farmers in Lagos state, Nigeria. Croatian Journal of Fisheries., 74(2): $56-70$.

Perey, E.R. 2016. Motivational Factors on the Adoption of Natural Farming Technology research. Journal of Agriculture and Forestry Sciences., 4(1):14-19.

Ragasa, C., Berhane, G., Tadesse, F. and Taffesse, A.S.2013. Effects of Extension Services on Technology Adoption and Productivity among Female and Male Farmers. Summary of ESSP Working Paper 49, ESSP research note.

Sadhu, A.N. and Singh, A. 1996. Farm size-productivity, Fundamentals of Agricultural Economics. Himalayan Publishing House. 186-211.

Sakib, M.H. and Afrad, M.S.I. 2014. Adoption of Modern Aquaculture Technologies by the Fish Farmers in Bogra District of Bangladesh. International Journal of Agriculture Innovations and Research. 3(2).

Sengupta, T. A. 1967. simple adoption scale for farmers for high yielding varieties of paddy. Indian Jour. of Exten.Edu., 3: $107-115$.

Sial, M.H., Iqbal, S. and Sheikh, A.D. 2012.Farm size-productivity' relationship Recent Evidence from Central Punjab Pakistan. Economic and Social Review., 50(2): 139-162.

Singh, K.M., Singh, R.K.P. and Kumar, A. 2014. Adoption of Modern Agricultural Technologies: A Micro Analysis at Farm Level in Bihar. Environment \& Ecology., 32(4): 13421346.

Sreenivasa, B.T. and Hiriyanna. 2014. A study on the factors influencing adoption of new technologies in non-traditional sericultural area of chitradurga district, Karnataka. g.j.b.a.h.s., 3(1): 239-243.

Stigler, S.M. (1974). Gergonne's 1815 paper on the design and analysis of polynomial regression experiments. Historia Mathematica. Vol. 1(4), pp.431-439.

Swathi, L.P.S., Balasubramani, N. and Chandrakandan, K. 2011. Diffusion of scientific shrimp farming through various stages of the adoption period. Tropical agricultural research \& extension., 14(4): 93-98.

Thapa, S.2007. The relationship between farm size and productivity: empirical evidence from the Nepalese mid-hills. Contributed paper prepared for presentation at the 106th seminar of the EAAE Pro-poor development in low income countries: Food, agriculture, trade, and environment, Montpellier, France.

Thompson, O.A. and Mafimisebi, T.E. 2014. Profitability of Selected Ventures in Catfish Aquaculture in Ondo State, Nigeria. Fisheries and Aquaculture Journal., 5:096. doi:10.4172/ 2150-3508.100096.

Tziraki, C., Graubard, B.I., Manley, M., Kosary, C., Moler, J.E. Edwards, B.K.2000. Effect of Training on Adoption of Cancer Prevention Nutrition-Related Activities by Primary Care Practices: Results of a Randomized Controlled Study. J Gen Intern Med., 15(3): 155-162.

Ureta, B.E., Cocchi, H. and Solis, D.2006. Adoption of soil Conservation Technologies in El Salvador: A Cross-Section and Over-Time Analysis. Office of Evaluation and Oversight, Inter-American Development Bank, December.

www.stata.com/manuals13/rlpoly.pdf, STATA manual, College Station, Texas 77845 USA. 